\title{
VIABILIDADE DE SEMENTES DE JILÓ EM FUNÇÃO DE DIFERENTES PERÍODOS DE ARMAZENAMENTO
}

\author{
Wilian Rodrigues Ribeiro' \\ André Alves Pinheiro ${ }^{2}$ \\ Melissa Alvarenga de Oliveira ${ }^{3}$ \\ Daniel Soares Ferreira ${ }^{4}$ \\ Leonardo Gonçalves Vargas ${ }^{5}$ \\ Gabriel Dias de Oliveira ${ }^{6}$ \\ José Carlos Lopes ${ }^{7}$
}

Resumo: A cultura do jiló é predominantemente propagada via seminífera. A qualidade da semente é fator primordial para sucesso da cultura, onde o ideal é que estas apresentem boa taxa de germinação e emergência. Porém dependendo da época e circunstancias às vezes torna-se necessário o armazenamento destas sementes, que podem vir afetar sua qualidade fisiológica, que podem ser avaliadas por sua viabilidade e vigor. Sendo assim, objetivou-se no presente estudo, verificar a influência de diferentes períodos de armazenamento sob a viabilidade de um lote de sementes de jiló, por testes de germinação e vigor, realizadas em placas de Petri e casa de vegetação. Foram avaliadas sementes de jiló não armazenadas (T0), armazenadas em câmara fria durante seis meses (T1) e armazenadas durante um ano (T2), ambos em recipiente de vidro. Verificou-se influência negativa no armazenamento das sementes de jiló, diminuindo assim sua viabilidade.

Palavras-chave: Viabilidade; Sementes; Deterioração; Solanum gilo.

\footnotetext{
${ }^{1}$ Agronomia/Universidade Federal do Espírito Santo/Alegre-ES, Brasil. E-mail: wilianrodrigues@msn.com.

${ }^{2}$ Agronomia/Universidade Federal do Espírito Santo/Alegre-ES, Brasil. E-mail: aalvespinheiro7@gmail.com.

3 Agronomia/Universidade Federal do Espírito Santo/Alegre-ES, Brasil. E-mail: melissalvarengao@gmail.com.

${ }^{4}$ Agronomia/Universidade Federal do Espírito Santo/Alegre-ES, Brasil. E-mail: danielufes@live.com.

5 Agronomia/Universidade Federal do Espírito Santo/Alegre-ES, Brasil. E-mail: leonardoovargasufes@hotmail.com.

${ }^{6}$ Agronomia/Universidade Federal do Espírito Santo/Alegre-ES, Brasil. E-mail: gabriel.dias.oliveira@gmail.com.

${ }^{7}$ Agronomia/Universidade Federal do Espírito Santo/Alegre-ES, Brasil. E-mail: jcufes@bol.com.br.
} 